\title{
Adölesan Dönemde Psikososyal Sorunlar
}

\author{
DOI: 10.26466/opus.906824
}

\author{
Ebru Akbaș* - Gülay Taşdemir Yiğitoğlu ** \\ * Dr. Öğr., Pamukkale Üniversitesi, SBF, Hemşirelik Anabilim Dalı, Denizli/Türkiye \\ E-Posta: ebruakbas1981@hotmail.com \\ ORCID: 0000-0002-9941-8436 \\ ** Dr. Öğr. Üyesi, Pamukkale Üniversitesi, SBF, Denizli/Türkiye \\ E-Posta: gyigitoglu@pau.edu.tr \\ ORCID: $\underline{0000-0002-8075-7155}$
}

\section{Öz}

Adölesan dönem; yaşam döngüsündeki en yoğun biyolojik ve sosyal değişim evresidir. Bu dönemde fiziksel ve cinsel alanda büyük değişimler olmaktadır. Bu da beden imajı, benlik algısı ve özsaygı üzerinde önemli etkilere yol açar. Kimlik oluşum süreciyle birlikte bilişsel gelişimin hızlanması, duygu yoğunluğunda artma, meslek seçimi, karşı cinsle kurulan ilişkiler, anne babadan ayrılma ve bireyselleşme sürecinin yaşanması gibi nedenlerle adölesan bireyler güçlük ve çatışma yaşamaktadır. Tüm bunlar adölesanların riskli davranışlarda bulunmasına neden olabilmektedir. Adölesan çağda tütün kullanımı, madde kullanımı ve korunmasız cinsel ilişki gibi riskli davranışlar sağglığı önemli ölçüde tehdit etmekte ve depresyon, davranış bozuklukları, yeme bozuklukları dahil çeşitli psikiyatrik hastalıkların görülme sıklı̆̆ı ve yaygınlı̆̆ı da artmaktadır. Adölesan dönem, sağlık açısından riskli davranışların tanınması ve korunma yollarının kazanılması açısından önemli bir dönemdir. Psikopatolojiyi ve hastalıkları önlemek, sağglılı gelişimi desteklemek için bu dönemde bireyler izlenmelidir. Bu döneme uyum sağlamada adölesanlara düzenli danışmanlık ve destek (stres yönetimi, öfke yönetimi, iletişim becerileri, cinsel sağlık eğitimi gibi) verilmesi onlarm riskli davranışlarında azalma sağlayabilir. Bu derlemenin amacı adölesanların riskli davranışlarının tanınması, bu davranışları önleyici yolların kazanılması için yapılacakları, literatür doğrultusunda tartışmak ve sonuçlarını değerlendirmektir.

Anahtar Kelimeler: $\quad$ Adölesan, Yeme Bozukluğu, Öfke, Şiddet, Cinsel Să̆lık. 


\title{
Psychosocial Problems in Adolescence
}

\begin{abstract}
Adolescence is the most intense biological and social change period in human life span. During adolescence, major changes occur both psychically and sexually. These changes effect body image, self-perception and self-esteem substantially. Identity development with cognitive growing, increase in emotional intensity, choosing a profession, relationships with opposite sex, separation from parents and becoming an individual, cause problems and conflicts in adolescents. These can also cause adolescent risk behaviours. Risk behavior such as smoking and substance abuse in adolescents, unprotected sexual relations with opposite gender are a threat to adolescent health. These risk behaviors also increase frequency and prevalence of depression, behavioral disorders, eating disorders and other psychiatric disorders. Adolescence is an important period for recognizing risk behavior, developing and applying protective ways against these risk behaviors. Individuals should be monitored during this period in order to prevent psychopathology and diseases and to support healthy development. Regular consultation and support (about stress management, anger management, communication skills, sexual health class etc.) to adolescents for their adaptation to changes, may help decrease these risk behaviors. This article aims to discusspotential ways and tools to determine adolescent risk behavior and to develop preventative ways against these risk behaviors; and evaluate the outcomes of these ways.
\end{abstract}

Keywords: Adolescence, Eating Disorder, Anger, Violence, Sexual Health. 


\section{Giriş}

Adölesan dönem; fiziksel büyüme, cinsel gelişme ve psikososyal olgunlaşmanın gerçekleştiği, çocukluktan erişkin hayata geçiş dönemidir. Bu dönem, insan gelişim dönemleri içinde en önemli evrelerden biridir (Parlaz, Tekgül, Karademirci, ve Öngel, 2013; Quinn, Rollock, ve Vrana, 2014). Adölesan bireyler bu döneme özgü bazı problemlerle karşı karşıya kalmaktadır. Bunların ortaya çıkmasına neden olan faktörler olarak; kimlik oluşum süreci içerisinde olma, bilişsel gelişimde hızlanma, duygu yoğunlunda artma, meslek seçimi, karşı cinsle ilişki kurma, anne babadan ayrılma ve bireyselleşme gibi nedenler gösterilebilir (Derman, 2008; Lowth, 2015; Quinn, Rollock, ve Vrana, 2014).

Adölesan dönem, nöroendokrin süreçlerde, hormonal değişimlerde ve fiziksel görünüşteki küçük değişikliklerle başlar ve üreme sisteminin olgunlaşmasıyla son bulur. Sosyal bir yapı olarak değerlendirilidiğinde ise daha karmaşık bir konsept ile karşılaşılmaktadır. Sosyal yönden farklı gruplara ait olma; benlik ve beden algısı, cinsel imaj ile kendisinden beklenen bağımsız ve olgun davranışlar sınırlarını belirlemede güçlük yaratmaktadır (Lowth, 2015; Quinn, Rollock, ve Vrana, 2014; Susman ve Rogol, 2004).

Dünya nüfusunun yaklaşık 1,8 milyarını adölesan dönemde bulunan gençler oluşturmaktadır (United Nations Population Fund [UNFPA], 2020). Dünya Sağlık Örgütü (DSÖ); bu gençlerin bir çoğunun sağlıklı olmakla birlikte önemli bir kısmının ciddi ve hatta ölümcül hastalıklar ya da çeşitli problemler yaşadığını belirtmektedir (Dünya Sağlık Örgütü [DSÖ], 2017). Dünyada adölesanlarda en sık görülen mortalite ve morbidite sebepleri; istenmeyen yaralanmalar ve kazalar, HIV-AIDS, diğer bulaşıcı hastalıklar (Helmint, tüberküloz, malaria gibi), savaş, katliam ve diğer bilinçli öldürme/yaralamalar, intihar ve kendine zarar vermeler, üreme sağlığı (gebelik ve doğum, kürtaj, cinsel yolla bulaşan hastalıklar, kadın sünneti gibi) sorunlarıdır (Blum ve Kristin, 2004; Taghizadeh Moghaddam, Bahreini, Ajilian Abbasi, Fazli, ve Saeidi, 2016).

Gençlerde ortaya çıkan bu riskli davranışlar, adölesanların ruh sağlığı ve iyiliğine olan etkileri düşünüldüğünde, kamu sağlığı için büyük bir endişe kaynağıdır (Bonell vd., 2015). Psikopatolojiyi ve hastalıkları önlemek, sağlıklı gelişimi desteklemek için bu dönemde hangi bireylerin başarılı bir yol 
izleyeceğini ve hangi bireylerin önemli problemlerle yüzleşeceğini öngörebilmek çok önemlidir (Compas, 2004). DSÖ (2021a) yaşamın erken aşamalarında ebeveyn ile çocuk arasında koruyucu ilişkileri desteklemenin, yaşam becerileri eğitimi sağlamanın, alkol ve silahlara erişimi azaltmanın, şiddet nedeniyle yaralanmaları ve ölümleri önlemeye yardımcı olabileceğini belirtmektedir.

Hızlı bir değişim ve gelişim süreci içerisinde olan adölesanlar, karşılaşabileceği olumsuz sonuçları göz ardı ederek bir çok riskli davranış sergilemeyi tercih edebilmektedir. Yaşamın diğer dönemlerine göre psikososyal sorunların ve risk alma davranışlarının çok daha fazla görüldüğü bu dönemde adölesan sağlığının korunması ve geliştirilmesi, yaşamlarını ve iyilik hallerini olumsuz yönde etkileyebilecek riskli davranışların önüne geçilmesi, bu davranışlarla mücadelede yetenek, beceri ve kapasitelerinin güçlendirilmesi adölesanların hem fiziksel hem de psikososyal sağlığını korumada ve geliştirmede büyük önem taşımaktadır.

\section{Adölesan Dönemin Gelişim Görevleri}

DSÖ (2021b) tarafından 10-19 yaş grubu “Adölesan" yaş grubu olarak nitelendirilmektedir. Yedi milyar üzerinde olan dünya nüfusunun $\% 23,7^{\prime} \operatorname{sini}$ 10-24 yaşları arasındaki gençler oluşturmakta ve bu nüfus gelişmekte olan ülkelerde gittikçe artmaktadır (UNFPA, 2020). Türkiye'nin 15-24 yaş grubundaki genç nüfusu, toplam nüfusun \%15,6'sını oluşturmaktadır (Türkiye İstatistik Kurumu [TÜİK], 2020).

Hızlı fiziksel, psikolojik ve sosyal değişimlerle karakterize olan bu dönemin başlangıcını ve ne kadar süreceğini belirlemek oldukça zordur. Bunun yanı sıra, bu dönemdeki normal ve anormallikleri belirlemek de güçtür (Parlaz vd., 2013; Susman ve Rogol, 2004). Adölesan dönemi psikososyal gelişim açısından, erken, orta ve geç adölesan dönemi olmak üzere üç bölümde ele alınmaktadır. Bu dönemler; Erken Adölesan Dönem (12-14 yaş), Orta Adölesan Dönem (15-18 yaş) ve Geç Adölesan Dönem (19-21 yaş) dir (Derman, 2008). Bu evrelerden geçen adölesanların gelişimlerine özgü davranış örüntülerini şu şekilde sıralayabiliriz:

- Bedensel özelliklerini kabul edip, etkili biçimde kullanır. Beden imajıyla barışık olmak ergenlikteki fiziksel değişiklikleri kabul etmek açısından oldukça önemlidir. 
- Aile içinde duygusal bağımsızlığını kazanır. Aileye ayrıntılı bilgi vermek veya önceden izin almak gibi davranışlarda bulunmak istemez.

- Mesleğine karar verir ve buna hazırlanır. Ne olacağına hangi alana veya üniversiteye gideceğine karar verir. Bu kararlarının ön hazırlıklarını gerçekleştirir.

- Erkek veya kadına ait toplumsal rolü gerçekleştirir. Cinsiyet rolü olarak toplumun atfettiği değerler doğrultusunda bir sosyal rolü benimser.

- Evliliğe ve aile yaşamına hazırlanır. Karşı cinsle olgun ilişkiler geliştirip, ailesi içinde duygusal bağımsızlığını kazanan genç kendi geleceğini, kuracağı aileyi düşünmeye başlar.

- Toplumsal temelde sorumlu bir davranış kazanmak ister. Gençler yetişkinlerin dünyası içerisinde bulunmak ve sorumluluk almak isterler.

- Değerleri oluşur ve ahlak sistemi gelişir. İdeolojilere duyarlıdırlar. Kendi değer sistemine uygun yönelimlerde bulunurlar (Baran ve Yurteri Tiryaki, 2016).

\section{Adölesan Döneminin Başlıca Sorunları}

Adölesan bireyler bu dönemde biyolojik, psikolojik ve sosyal yönden büyüme ve değişim süreci içerisindedirler. Deneyim arayışının en çok yaşandığı bu süreçte gençlerin bazı risklerle karşılaşmaya açık oldukları bilinmektedir. Buna karşılık sağlık sistemine başvuru sıklıkları diğer yaş gruplarına göre oldukça azdır. Karşılaşılan sağlık problemlerinin ise medikal olmaktan daha çok sosyal etkenlerle bağlantılı olduğu ve özellikle erken ergenlik dönemlerinde yapılacak sağlıkla ilgili girişimlerle mortalite ve morbidite oranlarının azaltılabileceği belirtilmektedir (Karabulut, 2019; Taghizadeh Moghaddam vd., 2016; Topçu Kabasakal, Sağkal, ve Türnüklü, 2015; Ünalan, Kaya, Akgün, Yıkılkan, ve İşgör, 2007). Taghizadeh Moghaddam vd. (2016)'ne göre adölesanların en yoğun biçimde yaşadığ fiziksel ve ruhsal problemler; adölesan gebelik ve doğum, riskli cinsel davranış ve üreme sağlığı sorunları, cinsel yolla bulaşan hastalıklar, psikolojik problemler, madde kullanımı, beslenme alışkanlıklarındaki sorunlar, kazalar, cinsel istismar ve şiddete yönelik davranışlardır. 


\section{Yeme Bozuklukları}

Yeme bozuklukları, altında karmaşık biyolojik ve psikolojik nedenler yatan, ciddi ancak tedavi edilebilir medikal hastalıklardır (Chavez ve Insel, 2007; Townsend, 2016). Yapılan çalışmalar kapsamında hem erkek hem kızlarda konulan yeme bozukluğu tanılarında önemli bir artış olduğu, uzun sürebildiği ve olumsuz sonuçlar gösterebildiği belirtilmektedir (Conti vd., 2017; Field vd., 2012; Micali, Hagberg, Petersen, ve Treasure, 2013). Yeme bozuklukları genelde başka bir psikiyatrik tanı ile birlikte görülür. Eş tanı olarak; depresyon, anksiyete, obsesif-kompulsif bozukluk, travma sonrası stres bozukluğu, kişilik bozuklukları, madde kötüye kullanım bozukluğu ve kendine zarar verici davranışlar olarak sıralanabilir (Chavez ve Insel, 2007; Conti vd., 2017; Sönmez, 2017). Yeme bozukluğu olan bireylerde tedavi sağlanamadığında kalp hastalıkları, böbrek yetmezliği gibi ölüme sebep olabilecek başka fiziksel sorunlarla da karşılaşılabilmektedir (Chavez ve Insel, 2007).

Yeme bozuklukları sıklıkla adölesan dönemde ve genç yetişkinlikte ortaya çlkar (Chavez ve Insel, 2007; Townsend, 2016). Birçok adölesan bu çağda stres gibi yaygın ruhsal problemler yaşamaktadır. Bu da adölesanın psikolojik sürecini, yeme alışkanlıklarını, yemek seçimlerini ve fiziksel aktivite aracılığıyla sağlığını etkilemektedir. Adölesan dönemde diyet alışkanlıkları oluşmakta ve bu hayatın sonraki aşamalarında hastalıkların görülmesini de etkilemektedir. Özellikle adölesan dönemde akut ya da kronik stresin yansımaları, yeme alışkanlıklarının değişimine yol açabilmektedir. Adölesan dönemde yaşanan stres daha çok yemek yemeye ve dolayıssyla kilo artışına sebep olmaktadır (Tajik, Zulkefli, Baharom, Minhat, ve Latiff, 2014). Çocuk ve adölesanlarda stres ve yeme alışkanlıkları üzerine yapılmış sistematik inceleme ve meta-analiz çalışmasında; stresin hem çocuk hem adölesanlarda (8-18 yaş arası) sağliksız beslenme alışkanlıklarıyla pozitif ilişkisi olduğu görülmüştür. Adölesanlarda sağlıklı beslenme alışkanlığı ile stres arasında ise negatif yönlü ilişkiye sahip olduğu tespit edilmiştir. Stres anında belli yiyecek tipleri ve beslenme tarzları olabilmektedir. Örneğin şekerli gıdalar, abur cubur dediğimiz enerji yüklü gıdalar stres ile daha çok yönelinen gıdalardır. Bu alışkanlıklar çocukluktan başlayıp adölesan dönemde kişiye yerleşerek, yetişkinliğe kadar devam edebilir. Obeziteye ve daha başka birçok sağlık sorununa sebep olabilir (Hill, 
Moss, Sykes-Muskett, Conner, ve O'Connor, 2018). Bu sebeple stresin beslenme alışkanlıkları üzerindeki etkisini tespit edip direkt ve dolaylı kapsamlı müdahaleler geliştirmek çocuk, adölesan ve yetişkinlerin sağlığını korumada oldukça önemlidir (Tajik vd., 2014; Hill vd., 2018).

Yeme bozuklukları çok az ve çok yeme kapsamında üç bölümde ele alınabilir. Bunlar: Anoreksiya Nervoza (AN), Bulimiya Nervoza (BN) ve Tikınırcasına Yeme Bozukluğu'dur (TYB). AN, psikiyatrik hastalıklar arasında yüksek morbidite ve mortalite oranına sahip ciddi bir psikiyatrik bozukluktur (Chesney, Goodwin, ve Fazel 2014; Herpertz-Dahlmann, 2015). Tipik olarak adölesan çağda başlayan bu bozukluk, çoğunlukla 12-18 yaş arası gençlerde \%1'den fazla görülmektedir (Le Grange, Hughes, Yeo, Crosby, ve Sawyer, 2016; Swanson, Crow, Le Grange, Swendsen, ve Merikangas, 2011). $\mathrm{Bu}$ bireylerde ciddi derecede düşük vücut ağırlığına sebep olacak şekilde kasıtlı olarak enerji alınımını kısıtlama davranışı söz konusudur. Diyet ve fazla egzersiz ile; bazı hastalar kendini kusturma, laksatif veya enema gibi yöntemlerle kilo vermektedir. Kilo alma ya da şişman olma korkusu önemli özelliklerindendir Hastalar kendilerini sürekli olarak çok şişman görmekte, vücut ağırlığından ve şeklinden rahatsızlık duymaktadır (Chavez ve Insel, 2007; Townsend, 2016). AN'den daha yaygın olan BN'nin görülme oranı kadınlarda \%4'tür (Townsend, 2016). Anoreksiya hastalarının aksine BN'de kişiler normal kilo ve vücut yapısında görünebilir ancak aşırı kilo alma korkusu, çaresizce kilo verme isteği semptomlarını taşırlar. Birey çok fazla yemek yedikten sonra kilo almaktan kaçınabilmek için telafi davranışları sergileyebilmektedir. Bu davranışlara örnek olarak; kendini kusturma, laksatifleri ve diüretikleri kötüye kullanma, uzun süre kendini aç bırakma ve aşırı egzersiz yapma verilebilir (Glasofer, Attia, ve Walsh, 2015; Townsend, 2016). Özellikle devamlı kusma sebebiyle de elektrolit dengesizliği, gastrointestinal problemler, ağız ve diş sağlığı problemleri görülebilen diğer sağlık sorunlarıdır (Chavez ve Insel, 2007; Setnick, 2010). Bulimiyadan farklı olarak tıkınırcasına yemede, kusma ya da başka bir telafi davranışı ile sonlanma görülmez. Sonuç olarak bu kişiler genelde aşırı kilolu ya da obez olurlar. Çoğunlukla suçluluk duygusu, tıkınırcasına yemeden doğan utanç ve stres daha fazla tıkınmaya yol açar. Obezite, kardiyovasküler problemler, hiperlipidemi, hipertansiyon gibi fizhayiksel hastalıklar TYB ile ilişkili bulunmuştur (Chavez ve Insel, 2007; Townsend, 2016). 
Çocuk ve adölesanlarda dürtüsel ve kontrolsüz yeme ile aşırı kilo ve obezitenin ilişkisinin incelendiği bir meta analiz çalışmasında dürtüsel/kontrolsüz yeme ile aşırı kilo ve obezitenin birbiriyle bağlantılı olduğu saptanmış ve dürtüsel yemenin işlevsel bir tedaviyle kilo alımını durdurabileceği ve böylelikle obezite riskinin de düşeceği belirtilmiştir (He, Cai, ve Fan, 2017). Tikınırcasına Yeme Bozukluğu (TYB) ve İntihar Eğilimi Arasındaki İlişkinin incelendiği başka bir sistematik bir İnceleme ise; TYB'nin, kendine zarar verme davranışı olarak tanımlandığında, hastaların hem kendilerine hem çevrelerine karşı çok agresif tavırlar sergilediğini belirtmiştir ve TYB'de intihar riskinde artışı ilişkilendirmiştir. İntihar davranışlarını önlemek adına geniş kapsamlı tedavilere ihtiyaç duyulduğu vurgulanmıştır (Conti vd., 2017).

Yeme bozukluklarında tedavide en önemli amaç bireyin beslenme davranışını düzenlemektir. Fiziksel durumu iyileştirme ve komplikasyonlanı önleme (aşırı zayıflama, dehidratasyon, sıvı ve elektrolit dengesizlikleri gibi) tedavide öncelikle ele alınması gereken durumlardır (Sönmez, 2017; Townsend, 2016). Bununla birlikte yeme bozukluklarında sıklıkla çok boyutlu tedavi yaklaşımı tercih edilmektedir. Bu yaklaşım içerisinde; fiziksel, psikolojik, psikososyal ihtiyaçlar ve bireyin ailesinden beklentileri yer almaktadır (Hay vd., 2014; Sönmez, 2017). Uygulanan tedavilere; davranış değişikliği tedavisi, bireysel terapi, bilişsel davranış̧̧ı terapi, psikofarmakoloji, motivasyonel terapi ve aile terapileri örnek olarak verilebilir (Sönmez, 2017; Townsend, 2016). Tedaviler üzerine yapılan kanıt temelli çalışmalarda ailenin çok önemli bir rol oynadığı ve başarıyı etkilediği gösterilmektedir (Govers vd., 2007; Le Grange vd., 2016; Yager vd., 2014).

\section{Cinsel Davranış Sorunları}

Kişilik yapısı ile birlikte cinsel organlarda fiziksel ve fonksiyonel değişikliklerin görüldüğü adölesan dönemde, ayrılma ve bireyselleşme süreçleri yaşanmakta ve cinsel kimlik duygusu olgunlaşmaktadır (Set, Dağdeviren, ve Aktürk, 2006). Adölesanların cinsel olarak olgunlaşan bedenlerine uyum göstermesi, kişiler arası ilişkilere yeni bir bakış getirmesi ve karar verme yeteneklerinin gelişmesi bu dönemde görülen önemli değişikliklerdir. Ancak 
gelişimsel olarak yaşanan bu hızlı değişimler cinsel yönden bazı riskli davranışların ortaya çıkmasına neden olmakla birlikte sağlık ve gelecek yönünden gençleri olumsuz etkileyebilmektedir (Çelik, Şule, ve Üstün 2018).

Cinsel davranışlar insan gelişiminin bir parçası ve gerekliliğidir. Cinsel gelişim döneminde olan adölesanın ileride sağlıklı bir cinsel hayatı ve buna bağlı olarak sağlıklı bir toplumsal rolü edinebilmesi için gerekli olan davranışların bütünü "Sorumlu cinsel davranış" şeklinde tanımlanmaktadır. Bu dönemde gösterilmesi gereken sorumlu cinsel davranışlar: erken cinsel ilişkiden kaçınmak, cinsel partnerin sık değişiminden uzak durmak, cinsel ilişki sırasında modern korunma yöntemlerini uygun şekilde kullanmak, cinsel yolla bulaşan hastalık ve istenmeyen gebelik riskinden korunmaktır (Yakut ve Özgü, 2013).

Adölesanın kişisel ve sosyal bir problem olarak cinsellikle ilgili riskli davranışları sosyal çevre ve kamu sağlığını da tehdit eder. Adölesan cinselliğinin erken dışavurumunun olumsuz sonuçları şu şekilde sıralanabilir:

- Adölesan gebelikler ve kürtaj

- Cinsel yolla bulaşan hastalıkların edinilmesi ve aktarılması

- Çok sik cinsel aktivite ve birden fazla cinsel partner

- Okula katılım, okuldaki başarı ve öğrenme motivasyonunun düşmesi

- Tütün, alkol, madde kullanımı ve yasadışı veya sapkın davranışlar (Çelik, Şule, ve Üstün, 2018; Savin-Williams ve Diamond, 2004).

Adölesanlarda cinsel konulardaki bilgi eksikliği ya da yanlış öğrenilmiş konular da bu dönem için ciddi bir sorundur (Bulut ve Gölbaşı, 2009). Bu dönemde adölesanların cinsel karar verme süreçlerine ilişkin ebeveyn davranışlarının da rolü büyüktür. Ebeveyn kontrolü ile adölesanların cinsellikle ilgili riskli davranışları arasındaki ilişkinin incelendiği bir meta-analiz çalışmasında; aktif gözlem ve kontrol uygulayan ebeveynlerin çocuklarının arkadaşları, bulundukları yerler ve aktiviteleri hakkında daha fazla bilgiye sahip oldukları belirlenmiştir. Kurallar uygulayan ebeveynlerin ise çocuklarının riskli davranıslarını yasaklar koyarak azaltabilecekleri belirtilmiştir. Sağlık çalışanlarının ebeveyn kontrolüne odaklanan aile-temelli müdahale girişimleri, adölesanların cinsel ve üreme sağlığını geliştirmek için önemli katkı sağlamaktadır (Dittus vd., 2015).

Her gencin cinselliğin psikolojisi, üreme sistemi ve ilgili konulardaki bilgi ihtiyacl; yaşına, cinsiyetine, yetiştiği kültüre, sosyo-ekonomik durumuna ve taşıdığı spesifik medikal/psikolojik problemlerine göre değişiklik 
göstermektedir (Bleakley, Hennessy, Fishbein, ve Jordan 2009; Yakut ve Özgü, 2013). Gençleri cinsel konulardaki bilgisizlikten, bilinçsiz ve riskli davranışların olumsuz sonuçlarından korumanın en etkili yolu uygun yaşta başlayan ve gencin ihtiyaç duyduğu bilgiyi zamanında karşılayan kapsamlı bir cinsel eğitimdir (Bulut ve Gölbaşı, 2009; Pringle vd., 2017). Sağlıklı cinsellik için verilecek olan bu eğitim sadece adölesan dönemde değil, çocukluk çağından itibaren evde, okulda, sağlık hizmeti alınan yerlerde ve toplum bazında yaşa uygun ve sürekliliği sağlayacak şekilde uygulanmalıdır (Bleakley vd., 2009; Yakut ve Özgü, 2013). Cinsel eğitim içeriğinde üreme sistemi organları ve fonksiyonları, adölesan gelişim döneminde yaşanan değişiklikler, cinsel ilişki ve gebelik, gebelikten korunma yöntemleri, cinsel yolla bulaşan hastalıklar, kişisel güvenlik vb. konular yer almalıdır (Çelik, Şule, ve Üstün, 2018; Yakut ve Özgü, 2013).

Ülkemizde okullarda henüz kapsamlı cinsel eğitim programları uygulanmadığı için, ailelerin cinsellikle ilgili konularda çocukları ile olan iletişimlerinin niceliği ve niteliği önem kazanmaktadır. Bu konuda çocuklarına en yakın birey olarak özellikle ebeveynlere önemli sorumluluklar düşmektedir. Ancak anne babaların çocuklarının cinsel eğitiminde etkili olabilmeleri için hem bilgi olarak yeterli olmaları hem de iletişim becerilerinin gelişmiş olması gereklidir. Ülkemizdeki ebeveynlerin de formal cinsel eğitim programlarından geçmedikleri, cinsellikle ilgili bilgilerini daha çok informal kaynaklardan ve deneyimlerinden öğrendikleri göz önüne alınırsa, cinsellikle ilgili konularda çocuklarına ne derece yardımcı olabildikleri bilinmemektedir (Bulut ve Gölbaşı, 2009). Ebeveyn-adölesan cinsel iletişimi, gençlikte daha güvenli cinsel davranışları pozitif etkileyebilecek bir faktör olarak değerlendirilmektedir (Widman vd., 2016). Bu sebeple ailelerin cinsel davranışları nasıl sınıflandıracağını bilmeleri çok önemlidir. Örneğin adölesanlar için; akranlar arasında açık seçik konuşmalar, müstehcenlik, şakalar, imalarda bulunma ve flört etme, mastürbasyon, kur yapma, sarılma ve öpüşme davranışları normal cinsel davranışlardır (McGrath, 2010). Adölesanların bu tür deneyimleri sonucu "sapık", "sapkın" gibi sifatlarla etiketlenmemeleri, benlik algısının gelişimsel süreci açısından çok önemli bir noktadır. Sağlıklı cinsel gelişimi desteklemede en güvenilir ve önemli cinsel eğitim bilgileri verebilecek grup sağlık çalışanlarıdır. Sağlık çalışanlarının bu eğitimi verirken uyması gereken bazı kurallar yer almaktadır. Bunlar; gizliliğin sağlanması, olay 
ya da durumun normalleştirilmesi, bireye saygı duyulması, kişisel yorumlamalardan kaçınılarak gerçek bilgilerin sunulması, tıbbi terimlerden uzak sade bir dil kullanılması, cinsellik açısından oluşabilecek risklerin yaşamın diğer alanlarını etkileyebileceğinin açıklanması, ihtiyaç duyacağı eğitimin devamı için güvenilir kaynak alternatiflerinin sunulmasıdır (Yakut ve Özgü, 2013).

Anormal cinsel davranışları hedef alırken, ergenin sağlık ve geleceğine nasıl bir tehlike oluşturduğu göz önüne alınarak (cinsel yolla bulaşan hastalıklar, madde kullanımı vb.) durum yönetilmeli, ruhsal problemler ve sosyal adaptasyon konularında da gereken uzman desteği verilmelidir. Yapılan bir sistematik derlemede, riskli cinsel davranışların yol açtığ olumsuz durumların kontrolünü sağlamada ve bu durumların gelişmesini önlemede cinsel sağlık eğitimi verilmesini, danışmanlık hizmeti sunulmasını ve doğum kontrol yöntemlerinin desteklenmesini önermektedir (Salam vd., 2016).

\section{Öfke ve Şiddet}

Öfke, olumsuz bir duygu olarak kabul görülsede, tehlikelere karşı harekete geçme, engellere karşı sabır gösterme ve benlik bütünlügünü koruma gibi olumlu niteliklere sahip olan bir duygudur (Kökdemir, 2004; Soykan, 2003). Öfkenin birçok nedeni olabilir. Bunlar; çevresel olaylar, psikolojik ve bilişsel süreçler, fizyolojik uyarılmaya neden olan faktörler, biyokimyasal süreçlerin varlığı gibi durumlardır (Novaco, 2017; Paull ve Gerhart; 2019; Şahin Kıralp ve Özben, 2013).

Bu duygunun en yoğun olarak yaşandığı adölesan dönemde, genç kızlar ve erkekler öfke duygunun yönetmede bazı sorunlar yaşayabilmektedir. Öfke deneyiminin kendisi her zaman olumsuz olmasa da, bu duyguyla nasıl baş edileceğini henüz bilmeyen bireyler öfkeyi uygun olmayan şekillerde dışavurabilir, bu da çeşitli problemlere yol açabilir. Saldırganlık, depresyon, intihar, madde kullanımı gibi pek çok problem öfke ile bağlantılıdır (Karabulut, 2019; Novaco, 2017; Shelley, 2012).

Öfkenin etkilerini anlamaya ek olarak, bazı gençlerin diğerlerine göre neden daha çok öfke duygusunu yaşadığını anlamak da önemlidir. Sosyal destek azlığı, zorbalık, aile içi olumsuz etkileşimler, kişilik özelliği, evdeki olumsuz ortam öfkeye neden olan faktörler olarak görülmektedir (Shelley, 
2012). Ayrıca diğer bir değişken olarak sosyoekonomik durumunda önemli etkisinin olduğu belirtilmektedir (Cantone vd., 2015).

Bu dönemde adölesan etkili iletişim kurabilme ve sağlıklı bir şekilde öfkeyi kontrol etmeyle ilgili sorunlar yaşamaktadır. Özellikle adölesan dönemde sosyal ilişkiler çok önemlidir. İletişim ve öfke kontrolüyle ilgili sorunlar adölesanın çevresiyle uyum sağlamasını güçleştirir ve şiddet eğilimini artırabilir (Keçialan ve Ocakçı, 2018). Buna ilave olarak aile örüntüsünde bozulma, sosyal izolasyon, okul başarısında düşme, yalnızlık, evden ya da okuldan kaçma gibi olumsuz durumlarla karşılaşılmasına neden olabilmektedir (Aydınl, 2014; Balc1 2019; Lowth, 2015).

Gençlerde zorbalık ve saldırganlık gibi şiddet içeikli davranışlar, adölesanların ruh sağlığı ve iyiliği açısından, kamu sağlığı için büyük bir endişe kaynağıdır (Bonell vd., 2015). Bu şiddet, fiziksel olduğu kadar psikolojik de meydana gelebilir. Okullarda sürekli olarak uygulandığını bildiğimiz bir şiddet türü zorbalıktır. Zorbalık sadece mağdur değil zorbanın kendisi açısından da çok fazla olumsuz etkiye yol açmaktadır. Yüksek stres seviyesine, antisosyal davranışlara ve suçlara bir risk faktörü olarak görülmektedir (Safaria ve Yunita, 2014). Zorbalık davranışlarına dahil olma, çocuk ve adölesanlarda sonradan ortaya çıkabilecek anksiyete, depresyon ve kendine zarar verme, madde kullanımı gibi ruh sağlığ problemlerine yol açabilmektedir (Bevilacqua vd., 2017). Ayrıca genç adölesan erkeklerde ölüm nedeni olarak şiddet davranışları ilk sıralarda görülmektedir (DSÖ, 2021a). Zorbalık ile intihar düşünceleri ve davranışlarının incelendiği bir meta-analiz çalışmasında; her bir zorbalık kategorisinde (mağdur, zorba, mağdur-zorba) intihar sonuçlarıyla önemli ilişkiler tespit edilmiştir. Tüm çalışmalarda, intihar düşünceleri ve davranışlarıyla zorbalık arasında ortalama veya ortalamadan fazla istatistiksel önemi olan bağlantı görülmüştür (Holt vd., 2015). Bu nedenle şiddetin davranışlarının fiziksel ve psikolojik sonuçlarıyla başa çıkmada, adölesanlarla kurulacak olan etkili iletişimin, empatik yaklaşımın ve gerekli desteğin verilmesi önem taşımakta ve sürecin devam ettirilmesinde yardımcı olmaktadır (DSÖ, 2021a).

Öfke ve korku duygularını kontrol edebilen, empati yeteneği olan, akranlarıyla iş birliği içerisinde olan, iletişim becerilerini kullanabilen gençlerin, göz korkutmak veya şiddet davranışları yerine çok yönlü, hoşgörülü, ve duyarlı bireyler olduğu belirtilmektedir (Marcus, 2017). Yaşamın erken aşamalarında ebeveyn ile çocuk arasında koruyucu ilişkileri desteklemek, yaşam 
becerileri eğitimi sağlamak, alkol ve silahlara erişimi azaltmak, şiddet nedeniyle yaralanmaları ve ölümleri önlemeye yardımcı olabilir (Eser ve Üstün, 2011). Okullarda yapılacak olan önleyici müdahaleler bu tür davranışların değişimi açısından oldukça önemli uygulamalardır (Gavine, Donnelly, ve Williams, 2016; Moore vd., 2017). Adölesan gruplara; öfke nedenleri, öfke ifade tarzları, öfke kontrolü, problem çözme basamakları, etkili iletişim ve sağlıklı baş etme becerileri kapsamında eğitim seminerleri düzenlenmelidir (Adana ve Arslantaş, 2011; Eser ve Üstün, 2011; Serin 2019). Ayrıca sağlık profesyonelleri tarafından bu dönemde yaşanan fiziksel ve ruhsal değişikliklere ilişkin bu gruba kapsamlı bilgiler verilmeli ve adölesanların bilgi kaynaklarına nasıl ulaşabileceği gösterilmelidir (Eser ve Üstün, 2011).

\section{Sonuç}

Gençler isteklerinin, ihtiyaçlarının ve duygularının anlaşılmasını; ebeveynlerin ve diğer yetişkinlerin onların fikirlerini kabul etmesini; kendileriyle ilgili kararlar alınırken aktif katılım gösterebilmesini; hatalarının yapıcı eleştirilerle aktarılmasını; bir yetişkin gibi problemlerin kendileriyle paylaşılmasını ve fikirlerinin sorulmasını isterler. Biyopsikososyal yönden hızlı ve değişken olan bu gençleri tanımak, onları anlamak, ihtiyaçlarını karşılamak ve sorularına hassasiyetle cevaplar vermek bu noktada atılacak önemli adımlardandır.

Adölesan dönem, sağlık açısından riskli davranışların tanınması, korunma yollarının kazandırılması ve sürdürülmesi açısından önemli fırsatların yakalanabileceği bir dönemdir. Gelişim görevlerini sağlamaya çalışan adölesanın, bu tür zorluklarla ve sağlık sorunlarıyla tek başına mücadele etmesini beklemek akılcı değildir. Bu süreçte adölesanın döneme özgü sorunlarıyla baş etmede yalnız bırakılması; adölesanda çaresizliğe yol açarak süreci yıkıcı ve yıpratıcı bir hale getirebilir. Dolayısıyla adölesanların herhangi bir problemle sağlık kurumlarına başvurmaların beklemek yerine toplum temelli hizmet girişimleri ile onlarla buluşmak ve onların dile getirdiği şekliyle ihtiyaçlarına karşılık vermek öncelikli olmalıdır.

Yeni düşüncelere açık olan ve karar verme konusundaki yeteneklerini geliştirmek isteyen adölesanların döneme özgü riskli davranışları tanıma ve bu davranışları önleme konusunda bilinçlendirilmesine yönelik yapılacak olan girişimler, rehberlik ve danışmanlık merkezlerinde, sosyal hizmet ya da 
sağlık hizmeti sunulan yerlerde gerçekleştirilebilir (Albayrak ve Kutlu, 2009; Anjanappa, Govindan, ve Munivenkatappa, 2020; Ünalan vd., 2007). Bu merkezlerde riskli grup olan adölesanlara döneme özgü fiziksel ve ruhsal değişikliklere yönelik çalışan profesyoneller (hemşireler, psikologlar, psikolojik danışmanlar gibi) tarafından kapsamlı bilgiler verilmeli ve onlara ulaşabileceği bilgi kaynakları öğretilmelidir (Eser ve Üstün, 2011). Bu grubun sağlığının korunması ve geliştirilmesi, sorunlarının çözümlenmesi ve hastalık halinde iyileştirilmesine yönelik yapılacak her türlü girişim ülkemizin gelişmişlik düzeyini artıracak ve geleceğe daha güvenle bakmamızı sağlayacaktır. 


\title{
EXTENDED ABSTRACT
}

\section{A Psychosocial Problems in Adolescence}

\author{
Ebru Akbaş- Gülay Taşdemir Yiğitoğlu \\ Pamukkale University
}

Introduction: Adolescent period is the transition period from childhood to adult life in which physical growth, sexual development and psychosocial maturation take place. This period is one of the most important stages of human development (Parlaz, Tekgül, Karademirci, ve Öngel, 2013; Quinn, Rollock, ve Vrana, 2014).

Adolescents, who are in a rapid change and development process, may exhibit varying risk behaviors by ignoring the negative consequences they may encounter. In this period, when psychosocial problems and risk-taking behaviors are more common than in others of life, preventing risk behaviors that may adversely affect their lives and well-being, and strengthening their abilities, skills and capacities in combating these behaviors are of great importance in protecting and improving adolescent health.

Developmental Tasks of the Adolescent Period: The 10-19 age group is defined as the "Adolescent" age group by WHO (2021b). Young people between the ages of $10-24$ constitute $23.7 \%$ of the world's population, which is over seven billion, and this population is increasing in developing countries (UNFPA, 2020). Turkey's young population in the 15-24 age group constitutes $15.6 \%$ of the total population (Turkish Statistical Institute [TUIK], 2020).

In terms of psychosocial development, the adolescence period is discussed in three parts; early, middle and late. These periods are namely; Early Adolescence (12-14 years), Middle Adolescence (15-18 years), and Late Adolescence (19-21 years) (Derman, 2008).

Major Problems of Adolescence Period:Adolescents are in a process of growth and change in biological, psychological and social aspects during this period. It is known that young people are open to encountering some risks in this process, where the search for experience is most common. 
Taghizadeh Moghaddam et al. (2016) state that physical and mental problems experienced by adolescents most intensely are adolescent pregnancy and birth, risky sexual behavior and reproductive health problems, sexually transmitted diseases, psychological problems, substance use, problems in eating habits, accidents, sexual abuse and violent behavior.

Eating Disorder: Eating disorders often develop in adolescence and young adulthood (Chavez ve Insel, 2007; Townsend, 2016). Many adolescents are experiencing common mental problems such as stress at this age. This affects the adolescent's psychological process, eating habits, food choices and health through physical activity. Dietary habits are formed in adolescence and this also affects the occurrence of diseases in the later stages of life. Repercussions of acute or chronic stress, especially in adolescence, can lead to changes in eating habits. Stress experienced during adolescence causes eating more and therefore weight gain (Tajik, Zulkefli, Baharom, Minhat, ve Latiff, 2014).

The most important goal when treating eating disorders is to regulate the nutritional behavior of the individual. Improving physical conditions and preventing complications (such as excessive weight loss, dehydration, fluid and electrolyte imbalances) are the conditions that should be addressed first in treatment (Sönmez, 2017; Townsend, 2016). However, a multidimensional treatment approach is often preferred in eating disorders. In this approach; physical, psychological, psychosocial needs and expectations of both individuals and their families are considered (Hay et al., 2014; Sönmez, 2017). Applied treatments are most commonly; behavioral change therapy, individual therapy, cognitive behavioral therapy, psychopharmacology, motivational therapy and family therapies (Sönmez, 2017; Townsend, 2016).

\section{Sexual Behavior Issue:}

As a personal and social problem of adolescents, risk behaviors related to sexuality also threaten the social environment and public health. The negative consequences of early expression of adolescent sexuality can be listed as follows:

- Adolescent pregnancies and abortions

- Acquisition and transmission of sexually transmitted diseases 
- Very frequent sexual activity and multiple sexual partners

- Decrease in school participation, success in school and learning motivation

- Tobacco, alcohol, substance use and illegal or deviant behavior (Çelik, Şule, ve Üstün, 2018; Savin-Williams and Diamond, 2004).

The most reliable and important sexual education information in supporting healthy sexual development can be provided by health professionals. There are some rules that health workers should follow while giving this training. Ensuring confidentiality, normalizing the event or situation, respecting the individual, presenting real information by avoiding personal interpretations, using a plain language away from medical terms, explaining that the risks that may occur in terms of sexuality may affect other areas of life, and providing reliable source alternatives for the continuation of the education that one will need, are some of these rules (Yakut et al. Ozgu, 2013).

Anger and Violence: Problems related to communication and anger control make it difficult for adolescents to adapt to their environment and may increase their tendency to violence (Keçialan ve Ocakçı, 2018). In addition, it can cause negative impacts such as deterioration in family pattern, social isolation, decrease in school success, loneliness, running away from home or school (Aydinll, 2014; Balc1 2019; Lowth, 2015). Violent behavior such as bullying and aggression in youth is a major concern for public health in terms of the mental health and well-being of adolescents (Bonell et al., 2015).

It is stated that young people who can control their feelings of anger and fear, have empathy skills, cooperate with their peers, and use their communication skills are versatile, tolerant and sensitive individuals instead of intimidating or violent (Marcus, 2017). Supporting protective relationships between parents and children in the early stages of life, providing life skills training, reducing access to alcohol and weapons can help prevent injuries and deaths due to violence (Eser \& Üstün, 2011). Preventive interventions in schools are very important practices in terms of changing such behaviors (Gavine, Donnelly, \& Williams, 2016; Moore et al., 2017). 


\section{Kaynakça / References}

Adana, F., ve Arslantaş, H. (2011). Ergenlikte öfke ve öfkenin yönetiminde okul hemşiresinin rolü. ADÜ Tıp Fakültesi Dergisi, 12(1), 57-62.

Albayrak, B. ve Kutlu, Y. (2009). Ergenlerde öfke ifade tarzı ve ilişkili faktörler. Maltepe Üniversitesi Hemşirelik Bilim ve Sanatı Dergisi, 2(3), 57-69.

Anjanappa, S., Govindan, R. ve Munivenkatappa, M. (2020). Prevalence and expression of anger in school going adolescents. Archives of Psychiatric Nursing, 34(1), 35-40.

Aydınl, S. (2014). Ergenlerin öfke ifade biçimleri, sosyal karşılaştırma düzeyleri, umutsuzluk seviyeleri ve çatışma çözme yaklaşımlarının incelenmesi. (Yayınlanmamış yüksek lisans tezi). Haliç Üniversitesi, Sosyal Bilimler Enstitüsü, Psikoloji Anabilim Dalı, İstanbul.

Balc1, E. (2019). Yetiştirme yurtlarında kalan ergenlerin saldırganlık ve öfke düzeyleri arasındaki ilişkinin incelenmesi. (Yayınlanmamış yüksek lisans tezi). Sabahattin Zaim Üniversitesi, Sosyal Bilimler Enstitüsü, Eğitim Bilimleri Anabilim Dalı, İstanbul.

Baran, G. ve Yurteri Tiryaki, A. (2016). Aile yaşam döngüsü. G. Baran (Der). Aile Yaşam Dinamiği içinde (s.17). Ankara, Pelikan Yayıncllık.

Bevilacqua, L., Shackleton, N., Hale, D., Allen, E., Bond, L., Christie, D., ... Viner, R. M. (2017). The role of family and school-level factors in bullying and cyberbullying: A cross-sectional study. BMC Pediatrics, 17(1), 1-10.

Bleakley, A., Hennessy, M., Fishbein, M. ve Jordan, A. (2009). How sources of sexual information relate to adolescents' beliefs about sex. Am J Health Behav, 33(1), 37-48.

Blum, R.W. ve Kristin, N.M. (2004). Adolescent health from an international perspectıve. R. M. Lerner ve L. Steinberg (Der). Handbook of Adolescent Psychology içinde (ss.553-571). New Jersey, Wiley \& Sons, Inc.

Bonell, C., Fletcher, A., Fitzgerald-Yau, N., Hale, D., Allen, E., Elbourne, D., ...Viner, R. (2015). Initiating change locally in bullying and aggression through the school environment (Inclusive): A pilot randomised controlled trial. Health Technology Assessment, 19(53), 1-110.

Bulut, F., ve Gölbaşı, Z. (2009). Adolesan kızların cinsellikle ilgili konularda anneleri ile olan iletişimlerinin değerlendirilmesi. TAF Preventive Medicine Bulletin, $8(1), 27-36$. 
Cantone, E., Piras, A. P., Vellante, M., Preti, A., Daníelsdóttir, S., D’Aloja, E., ...Bhugra, D. (2015). Interventions on bullying and cyberbullying in schools: A systematic review. Clinical practice and epidemiology in mental health: $C P \mathcal{E} E M H$, 11(Suppl 1 M4), 58.

Çelik, H. K., Şule, Ö. ve Üstün, Y. E. (2018). Adolesanlarda cinsel sağlık ve üreme sağlığı. Jinekoloji-Obstetrik ve Neonatoloji Tıp Dergisi, 15(4), 184-188.

Chavez, M. ve Insel, T. R. (2007). Eating disorders: National Institute of Mental Health's perspective. American Psychologist, 62(3), 159-166.

Chesney, E., Goodwin, G. M. ve Fazel, S. (2014). Risks of all-cause and suicide mortality in mental disorders: A meta-review. World Psychiatry, 13, 153-160.

Compas, B. E. (2004). Processes of risk and resilience during adolescence. R. M. Lerner ve L. Steinberg (Der). Handbook of Adolescent Psychology içinde (s.263). New Jersey, Wiley \& Sons, Inc.

Conti, C., Lanzara, R., Scipioni, M., Iasenza, M., Guagnano, M. T. ve Fulcheri, M. (2017). The relationship between binge eating disorder and suicidality: A systematic review. Frontiers in Psychology, 8, 2125.

Derman, O. (2008). Ergenlerde psikososyal gelişim. Adolesan Să̆̆ı̆̆ı II Sempozyum Dizisi, 63, 19-21.

Dittus, P. J., Michael, S. L., Becasen, J. S., Gloppen, K. M., McCarthy, K. ve GuilamoRamos, V. (2015). Parental monitoring and its associations with adolescent sexual risk behavior: A meta-analysis. Pediatrics, 136(6), e1587-e1599.

Dünya Sağlık Örgütü. (2017). More than 1.2 million adolescents die every year, nearly all preventable. 25 Şubat 2021 tarihinde, https://www.who.int/en/news-room/detail/16-05-2017-more-than-1-2-million-adolescents-die-every-year-nearly-all-preventable adresinden erişildi.

Dünya Sağlık Örgütü. (2021). Adolescent health. 25 Şubat 2021 tarihinde, https://www.who.int/health-topics/adolescent-health\#tab=tab_1 adresinden erişildi.

Dünya Sağlık Örgütü. (2021a). Adolescent and young adult health. 30 Mart 2021 tarihinde, https://www.who.int/en/news-room/fact-sheets/detail/adolescents-healthrisks-and-solutions adresinden erişildi.

Eser, D. T. ve Üstün, B. (2011). Psikiyatrik bozukluğu olan ergen ve ebeveynlerinin öfke ifade biçimleri arasındaki ilişkinin incelenmesi. Psikiyatri Hemşireliği Dergisi, 2(3), 111-116.

Field, A. E., Sonneville, K. R, Micali, N., Crosby, R. D., Swanson, S. A., Laird, N. M.,...Horton, N. J. (2012) Prospective association of common eating disorders and adverse outcomes. Pediatrics, 130(2), e289-295. 
Gavine, A. J., Donnelly, P. D. ve Williams, D. J. (2016). Effectiveness of universal school-based programs for prevention of violence in adolescents. Psychology of Violence, 6(3), 390-399.

Glasofer, D. R, Attia, E., Walsh, B. T. (2015). Feeding and eating disorders. A. Tasman, J. Kay, J. A. Lieberman, M. B. First, M. B. Riba (Der.), Psychiatry içinde (s.1231-1249). New York, Wiley.

Gowers, S. G., Clark, A., Roberts, C., Griffiths, A., Edwards, V., Bryan, C., ... Barrett, B. (2007). Clinical effectiveness of treatments for anorexia nervosa in adolescents: Randomised controlled trial. The British Journal of Psychiatry, 191(5), 427-435.

Hay, P., Chinn, D., Forbes, D., Madden, S., Newton, R., Sugenor, L., ...Ward, W. (2014). Royal Australian and New Zealand College of Psychiatrists clinical practice guidelines for the treatment of eating disorders. Austr N Z JPsychiatry, 48(11), 977-1008.

He, J., Cai, Z. ve Fan, X. (2017). Prevalence of binge and loss of control eating among children and adolescents with overweight and obesity: An exploratory meta-analysis. International Journal of Eating Disorders, 50(2), 91-103.

Herpertz-Dahlmann, B. (2015). Adolescent eating disorders: update on definitions, symptomatology, epidemiology, and comorbidity. Child Adolesc Psychiatr Clin North Am, 24, 177-196.

Hill, D. C., Moss, R. H., Sykes-Muskett, B., Conner, M., ve O'Connor, D. B. (2018). Stress and eating behaviors in children and adolescents: Systematic review and meta-analysis. Appetite, 123, 14-22.

Holt, M. K., Vivolo-Kantor, A. M., Polanin, J. R., Holland, K. M., DeGue, S., Matjasko, J. L., ...Reid, G. (2015). Bullying and suicidal ideation and behaviors: A metaanalysis. Pediatrics, 135(2), e496-e509.

Karabulut, B. (2019). Ortaöğretim öğrencilerinde dijital oyun bağımlilığı ve şiddet eğilimi ilişkisi. (Yayımlanmamış yüksek lisans tezi). Hasan Kalyoncu Üniversitesi, Sosyal Bilimler Enstitüsü, Psikoloji Anabilim Dall, Gaziantep.

Keçialan, R., ve Ocakçı, A. F. (2018). Ergenlere yapilan sosyal beceri eğitiminin iletişim ve öfke kontrolüne etkisi. Medical Sciences, 13(3), 58-65.

Kökdemir, H. (2004). Öfke ve öfke kontrolü. Pivalko, 3, 7-10.

Le Grange, D., Hughes, E. K., Yeo, M., Crosby, R. D. ve Sawyer, S. M. (2016). Randomized clinical trial of parent-focused treatment and family-based treatment for adolescent anorexia nervosa. Journal of the American Academy of Child \& Adolescent Psychiatry, 55(8), 683-692.

Lowth, M. (2015). Managing anger in adolescents. Practice Nurse, 45(12), 18-23. 
Marcus, R. F. (2017). The Development of aggression and violence in adolescence. New York: Springer.

McGrath, K. (2010). Understanding\&Managing sexualised behaviour in children\&adolescents guidelines for parents\&carers, The CARI Foundation, 1-23.

Micali, N., Hagberg, K. W., Petersen, I., ve Treasure, J. L. (2013). The incidence of eating disorders in the UK in 2000-2009: Findings from the general practice research database. BMJ open, 3(5), e002646.

Moore, S. E., Norman, R. E., Suetani, S., Thomas, H. J., Sly, P. D. ve Scott, J. G. (2017). Consequences of bullying victimization in childhood and adolescence: A systematic review and meta-analysis. World Journal of Psychiatry, 7(1), 60.

Novaco, R. W. (2017). Anger. V. Zeigler-Hill, T. K. Shackelford (Der.), Encyclopedia of personality and individual içinde (s.1-5). Switzerland, Springer International Publishing.

Parlaz, E. A., Tekgül, N., Karademirci, E. ve Öngel, K. (2013). Ergenlik dönemi: Fiziksel büyüme, psikolojik ve sosyal gelişim süreci. Turkısh Family Physıcıan, 3(2), 10-16.

Pringle, J., Mills, K. L., McAteer, J., Jepson, R., Hogg, E., Anand, N. ve Blakemore, S. J. (2017). The physiology of adolescent sexual behaviour: A systematic review. Cogent social sciences, 3(1), 1368858.

Quinn, C.A., Rollock, D. ve Vrana, S.R. (2014). A test of Spielberger's state-trait theory of anger with adolescents: Five hypotheses. Emotion, 14(1), 74.

Safaria, T. ve Yunita, A. (2014). The efficacy of art therapy to reduce anxiety among bullying victims. International Journal of Research Studies in Psychology, 3(4), 7788.

Şahin Kıralp, F. ve Özben, Ş. (2015). İköğretim II. kademe öğrencilerinin öfke yaşantılarının belirlenmesi. Turkish International Journal of Special Education and Guidance \& Counselling (TIJSEG), 4(2), 24- 32.

Salam, R. A., Faqqah, A., Sajjad, N., Lassi, Z. S., Das, J. K., Kaufman, M. ve Bhutta, Z. A. (2016). Improving adolescent sexual and reproductive health: A systematic review of potential interventions. Journal of Adolescent Health, 59(4), 11-28.

Savin-Williams, R. C. ve Diamond, L. M. (2004). Sex. R. M. Lerner ve L. Stemberg (Der.), Handbook of Adolescent Psychology içinde (ss.189-231). New Jersey, Wiley \& Sons, Inc.

Serin, N. B. (2019). The impact of anger management training on anger, aggression and problem-solving skills of primary school students. International Online Journal of Education and Teaching, 6(3), 525-543. 
Set, T., Dağdeviren, N. ve Aktürk, Z. (2006). Ergenlerde cinsellik. Genel Tıp Dergisi, 16(3), 137-141.

Setnick, J. (2010). Micronutrient deficiencies and supplementation in anorexia and bulimia nervosa a review of literature. Nutr Clin Pract, 25, 137-142.

Shelley, B. N. (2012). Causes and effects of adolescent anger. A capstone project in partial fulfillment of the requirements for the masters of science degree in professional development, Winona State University, Minnesota.

Sönmez, A. Ö. (2017). Çocuk ve ergenlerde yeme bozuklukları. Psikiyatride Güncel Yaklaşımlar, 9(3), 301-316.

Soykan, Ç. (2003). Öfke ve öfke yönetimi. Kriz Dergisi, 11(2), 19-27.

Susman, E.J. ve Rogol, A. (2004). Puberty and psychological development. R. M. Lerner ve L. Steinberg (Der.), Handbook of Adolescent Psychology içinde (s.15-44). New Jersey, Wiley \& Sons, Inc.

Swanson, S. A., Crow, S. J., Le Grange, D., Swendsen, J. ve Merikangas, K. R. (2011). Prevalence and correlates of eating disorders in adolescents: Results from the national comorbidity survey replication adolescent supplement. Arch Gen Psychiatry, 68, 714-723.

Taghizadeh Moghaddam, H., Bahreini, A., Ajilian Abbasi, M., Fazli, F. ve Saeidi, M. (2016). Adolescence health: The needs, problems and attention. International Journal of Pediatrics, 4(2), 1423-1438.

Tajik, E., Zulkefli, N. A. M., Baharom, A., Minhat, H. S. ve Latiff, L. A. (2014). Contributing factors of obesity among stressed adolescents. Electronic Physician, 6(1), 771.

Topçu Kabasakal, Z., Sağkal, A. S. ve Türnüklü, A. (2015). Barış eğitimi programının öğrencilerin şiddet eğilimleri ve sosyal sorun çözme becerileri üzerindeki etkileri. Ĕ̆itim ve Bilim, 40(182), 43-62.

Townsend, M. C. (2016). Ruh sağhlğ̆ ve psikiyatri hemşireliğinin temelleri kanıta dayalı uygulama bakım kavramları. (C. T. Özcan ve N. Gürhan, Çev.). Ankara, Akademisyen Tip Kitabevi.

Türkiye İstatistik Kurumu. (2020). İstatistiklerle gençlik, 2019. 30 Mart 2021 tarihinde, https://tuikweb.tuik.gov.tr/PreHaberBultenleri.do?id=33731 adresinden erişildi.

Ünalan, P. C., Kaya, Ç. A., Akgün, T., Yıkılkan, H. ve İşgör, A. (2007). Birinci basamakta ergen sağlığına yaklaşım. Turkiye Klinikleri J Med Sci, 27, 567-576.

United Nations Population Fund. (2020). Dünya nüfusu göstergesi. 27 Şubat 2021 tarihinde, https://www.unfpa.org/data/world-population-dashboard adresinden erişildi. 
Widman, L., Choukas-Bradley, S., Noar, S. M., Nesi, J. ve Garrett, K. (2016). Parentadolescent sexual communication and adolescent safer sex behavior: A meta-analysis. JAMA Pediatrics, 170(1), 52-61.

Yager, J., Devlin, M. J., Halmi, K. A., Herzog, D. B., Mitchell, J. E., Powers, P. ve Zerbe, K. J. (2014). Guideline watch (August 2012): Practice guideline for the treatment of patients with eating disorders. Focus, 12(4), 416-431.

Yakut, H. İ. ve Özgü, B. S. (2013). Adolesanlarda cinsel eğitim. Jinekoloji-Obstetrik ve Neonatoloji Tip Dergisi, 10(39), 1633-1635.

Yıldırımkaya, G. (2008). Türkiye'de karşılanmamış cinsel sağlık bilgisi ihtiyacının adolesan sağlığına yansıması ve UNFPA. İ.Ü. Cerrahpaşa tıp fakültesi sürekli tıp eğitimi etkinlikleri, 47-50.

\section{Kaynakça Bilgisi / Citation Information}

Akbaş, E. ve Taşdemir Yiğitoğlu, G. (2021). Adölesan dönemde psikososyal sorunlar. OPUS-Uluslararası Toplum Araştırmaları Dergisi, 18(43), 7277-7299. DOI: 10.26466/opus. 906824. 